\title{
Patterns of beverage consumption and risk of CHD among Mexican adults
}

\author{
Berenice Rivera-Paredez ${ }^{1}$, Paloma Muñoz-Aguirre ${ }^{2 *}$, Leticia Torres-Ibarra ${ }^{2}$, Paula Ramírez ${ }^{1}$, \\ Rubí Hernández-López ${ }^{3}$, Elizabeth Barrios ${ }^{3}$, Leith León-Maldonado ${ }^{4}$, Edgar Denova-Gutiérrez ${ }^{5}$, \\ Mario Flores ${ }^{5}$, Eduardo Salazar-Martínez ${ }^{2}$ and Jorge Salmerón ${ }^{1,2}$ \\ ${ }^{1}$ Unidad de Investigación Epidemiológica y en Servicios de Salud, Instituto Mexicano del Seguro Social, 62000 Cuernavaca, \\ Mexico \\ ${ }^{2}$ Centro de Investigación en Salud Poblacional, Instituto Nacional de Salud Pública, 62100 Cuernavaca, Mexico \\ ${ }^{3}$ Escuela de Salud Pública de México, Instituto Nacional de Salud Pública, 62100 Cuernavaca, Mexico \\ ${ }^{4}$ Centro de Investigación en Salud Poblacional (CONACYT), Instituto Nacional de Salud Pública, 62100 Cuernavaca, Mexico \\ ${ }^{5}$ Centro de Investigación en Nutrición y Salud, Instituto Nacional de Salud Pública, 62100 Cuernavaca, Mexico
}

(Submitted 23 March 2017 - Final revision received 21 February 2018 - Accepted 7 March 2018)

\section{Abstract}

CHD is becoming an increasing priority worldwide, as it is one of the main causes of death in low- and middle-income countries lately. This study aims to evaluate the association between beverage consumption patterns and the risk of CHD among Mexican adult population. We performed a cross-sectional analysis using data from 6640 adults participating in the Health Workers' Cohort Study. Factor analysis was performed to identify beverage patterns using sex-specific Framingham prediction algorithms to estimate CHD risk. The prevalence of moderate to high CHD risk was $17 \cdot 8 \%$. We identified four major beverage consumption patterns, which were categorised as alcohol, coffee/ tea, soft drinks and low-fat milk. We observed a lower risk of CHD (OR=0.61; $95 \%$ CI 0.46, 0.80; and OR=0.58; $95 \%$ CI 0.43 , 0.79, respectively) among participants in the upper quintile of alcohol or low-fat milk consumption compared with those in the bottom quintile. In contrast, a higher consumption of soft drinks was positively associated with CHD risk (OR $=1 \cdot 64 ; 95 \%$ CI $1 \cdot 21,2 \cdot 20)$ when compared with other extreme quintiles. Finally, coffee/tea consumption was not significantly associated with CHD risk. Our findings suggest that a beverage pattern characterised by a higher intake of sugar-sweetened beverages may be associated with an increased risk of CHD among the Mexican adult population, whereas patterns of moderate alcohol intake and low-fat milk may be associated with a reduced risk.

Key words: CHD: Beverage patterns: Soft drinks: Alcohol: Mexican adults

CHD is a major public health problem worldwide, and it has become one of the leading causes of morbidity and mortality in several countries ${ }^{(1)}$. The World Health Organization ${ }^{(2)}$ estimated that 17.5 million people died from CVD in 2012 , and of these 7.4 million deaths were due to CHD, with over $80 \%$ of them occurring in low- and middle-income countries. According to the analysis of the Global Burden of Disease in Mexico, IHD is the leading cause of years of life lost ${ }^{(3)}$.

The occurrence of CHD is mainly determined by pre-existing clinical conditions such as hypertension, dyslipidaemia and type 2 diabetes $^{(4)}$. All of these chronic diseases are highly prevalent among the Mexican population, leading to increased $\mathrm{CHD}$ risk at younger ages ${ }^{(5)}$.

Specific lifestyle patterns, particularly diet, are strongly associated with these cardio-metabolic disorders ${ }^{(6)}$. There is a need to identify lifestyle patterns that may help to reduce CHD risk in our population, such as beverage consumption patterns ${ }^{(7)}$. Previous studies suggest that moderate alcohol intake is inversely associated with $\mathrm{CHD}^{(8-10)}$. The cardio-protective effect of moderate alcohol consumption may be related to changes in lipoprotein profiles, inflammatory cytokines (IL 6, C-reactive protein and TNF- $\alpha$ ) and insulin resistance ${ }^{(8,11)}$. In addition, increased sugar-sweetened beverages (SSB) intake has been associated with insulin resistance, lower HDL-cholesterol, higher deposit of visceral fat and increased TAG concentrations, as well as the metabolic syndrome ${ }^{(12-15)}$.

Increased SSB consumption trends during the past several decades subsequently suggest that there are significant changes to the general Mexican population nutritional profile ${ }^{(16)}$. Mexico is the world's largest per capita consumer of SSB. For this reason, it is important to explore the potential effects of these new beverage consumption patterns on $\mathrm{CHD}$ within the Mexican population. From 2006 to 2012, SSB has led to a marked increase in per capita energy consumption ${ }^{(16,17)}$. Analysis of consumption patterns provides additional information on the potential effects coming from the consumption of specific beverages, which cannot be determined when only individual beverage consumption patterns are

Abbreviation: SSB, sugar-sweetened beverages.

* Corresponding author: P. Muñoz-Aguirre, email pmz.aguirre@gmail.com 
examined $^{(18)}$. Thus, the purpose of this study is to identify beverage consumption patterns and their potential relationship with $\mathrm{CHD}$ risk among the Mexican adult population.

\section{Methods \\ Study population}

We performed a cross-sectional analysis of the baseline assessment of the Health Workers' Cohort Study (HWCS). The study design, methodology and participants' baseline characteristics have been described elsewhere ${ }^{(19)}$. The original study's purpose was to assess the relationship between lifestyles and health outcomes with data from workers at the Instituto Mexicano del Seguro Social (IMSS, by its acronym in Spanish) and the Instituto Nacional de Salud Pública (INSP, by its acronym in Spanish), which are both located at the Universidad Autónoma del Estado de México in Cuernavaca Morelos (UAEMex, by its acronym in Spanish). The HWCS is a dynamic cohort study with data from 10079 subjects aged between 18 and 85 years including active and retired workers, as well as their families ${ }^{(15,19)}$.

Of the 10079 Mexican women and men, we excluded subjects who did not meet the age criteria (20-70, $n$ 1267), subjects with a prior CVD diagnosis ( $n$ 412), subjects with weight change $>10 \mathrm{~kg}$ in the last year ( $n$ 137), any outlier energy values $(<2510 \cdot 4$ and $>29288 \mathrm{~kJ} / \mathrm{d}(<600$ and $>7000 \mathrm{kcal} / \mathrm{d}))^{(20)}(n$ 142), subjects with missing information on smoking ( $n$ 294), BMI ( $n$ 428), physical activity ( $n$ 130), LDL-cholesterol and HDL-cholesterol ( $n$ 584). In addition, we excluded subjects with serum creatinine $>176.8 \mu \mathrm{mol} / \mathrm{l}(n$ 9) and women with missing information on menopausal status ( $n$ 36). After excluding subjects who did not meet our study criteria, a total of 6640 subjects aged 20-70 years were included in the final analysis.

All participating institutions' research ethics committees (Comité de Ética en Investigación, IMSS (no. 12CEI 09006 14); Comité de ética en Investigación, INSP (no. 13CEI 17007 36); Comité de Ética, Centro de Investigación en Ciencias Médicas (no. 1233008 ×0236)) revised and approved the study protocol and informed consent forms. Written informed consent was obtained from each participant.

\section{Dietary assessment}

A previously validated ${ }^{(21)}$ semi-quantitative FFQ was used to assess diet through collecting data on the frequency of consumption of 116 food items during the previous year. For each food item, a commonly used portion size (e.g. one slice of bread) was specified and participants were asked how frequently they had consumed the food over the previous year. They were able to choose from ten responses ranging from 'never' to 'six or more times per day'. The energy and nutrient intake was estimated by multiplying the frequency of consumption of each food type included in the FFQ by the nutrient content estimated with a comprehensive database of food contents ${ }^{(19,22)}$.

\section{Beverage patterns}

To determine beverage consumption patterns, we started by first grouping all beverages into eight different categories according to their energy and nutrient density contribution to total energy intake, fat content and alcohol content. The categories were high-fat milk (whole milk; coffee with milk; atole with milk and chocolate with milk); low-fat milk (reduced fat and skimmed milk); homemade sweetened beverages (fruitflavoured or artificial); soft drinks (soda); diet drinks (lowenergy drinks); other sweetened beverages (coffee, atole, chocolate and tea without milk); alcoholic beverages (beer, whisky, brandy, tequila, rum, hard liquor and pulque); and wine. Wine was placed in a separate category from the other alcoholic beverages because it has greater antioxidant and antiinflammatory activity ${ }^{(23)}$. Second, we converted drink volume $(\mathrm{ml})$ into a portion of the total volume/d and standardised using $z$ scores. Third, using a principal components analysis of the beverage groups, beverage consumption patterns were categorised. The factors (beverage patterns) were orthogonally rotated (varimax rotation) in order to ensure that they were uncorrelated and to make their interpretation easier to understand. Factor values were determined after the assessment of eigenvalues, graphic analysis and interpretability. Each factor was defined by a subgroup that placed drinks on the axis of the factor, with an absolute $\operatorname{load} \geq 0 \cdot 3$ (groups with a factor of load $\geq 0.3$ will be considered as a significant contribution to the beverage pattern $)^{(24)}$. The derived factors were labelled in relation to make the data easily interpretable. Each factor was defined by a subset of drinks with an absolute $\geq 0.3$ load factor (considering that $\geq 0.3$ load factors contributed significantly to the dietary pattern $)^{(24)}$. These factors were labelled in a way that could be easily interpreted.

\section{Assessment of non-dietary variables}

Demographic characteristics were evaluated from data reported on self-administered questionnaires. Physical activity was assessed using the International Physical Activity Questionnaire (IPAQ) adapted to the Mexican population ${ }^{(19,25)}$. In this questionnaire, participants reported time spent practising specific activities in their free time through sixteen questions that also assessed the time dedicated by each person per week to these activities. These activities included physical activity such as walking, running and cycling. Work-related physical activity was also assessed through eight questions on activities such as sitting, standing, walking, lifting and using heavy machinery during a typical week of the previous year ${ }^{(19,25)}$.

\section{Anthropometric and clinical assessment}

Weight was measured using a previously calibrated electronic scale (model BC-533; TANITA) with participants wearing minimum clothing and no shoes. Height was measured using a conventional stadiometer while the subjects were standing, barefoot, with both shoulders aligned. Waist circumference was assessed to the nearest $0 \cdot 1 \mathrm{~cm}$ at the high point of the iliac crest at the end of normal expiration; the tape was placed below any clothing, directly touching the participant's skin. BMI $\left(\mathrm{kg} / \mathrm{m}^{2}\right)$ was derived by dividing the body weight $(\mathrm{kg})$ by the height squared $\left(\mathrm{m}^{2}\right)$. Proportion of body fat was estimated by means of dual-energy X-ray absorptiometry performed with a Lunar DPXL densitometer (Lunar Radiation Corp. software version 1.35, fast scan mode; model: DPX-NT 73735, series: 638405U77). 
Blood pressure was measured with an electronic digital blood pressure monitor. Participants were seated with their right arm resting at heart level. For the participants from UAEM, three blood pressure measurements were obtained and the mean of the last two measurements was used to assess CHD risk. For the participants from INSP and IMSS, one blood pressure measurement was obtained. Measurement of these anthropometric criteria and blood pressure was performed by nurses trained to perform standardised procedures (reproducibility was evaluated, resulting in a concordance coefficient of 0.83-0.90). A fasting venous blood sample (fasting time was $\geq 8 \mathrm{~h}$ ) was collected from each participant. HDL-cholesterol was measured by the clearance method, in which non-HDL-cholesterol lipoprotein is removed in the first step of the reaction (clearance step); LDL-cholesterol was also measured by the clearance method. Total cholesterol was measured by colorimetric method following the enzymatic assay. Plasma TAG were measured with a colorimetric method following enzymatic hydrolysis performed with the lipase technique. All biomedical assays were performed using a Selectra XL instrument (Randox), in concordance with the proceedings of the International Federation of Clinical Chemistry and Laboratory Medicine $^{(26)}$. The cardiovascular risk factors were defined according to the criteria of the National Cholesterol Education Program ATP-III, as follows: high serum TAG $\geq 150 \mathrm{mg} / \mathrm{dl} \quad(\geq 1.7 \mathrm{mmol} / \mathrm{l})$, high serum total cholesterol $\geq 200 \mathrm{mg} / \mathrm{dl}(\geq 5.2 \mathrm{mmol} / \mathrm{l})$, high LDLcholesterol $\geq 100 \mathrm{mg} / \mathrm{dl}(\geq 2.6 \mathrm{mmol} / \mathrm{l})$ and low HDL-cholesterol $<40 \mathrm{mg} / \mathrm{dl}(<1.0 \mathrm{mmol} / \mathrm{l})$ for men and $<50 \mathrm{mg} / \mathrm{dl}(<1.3 \mathrm{mmol} / \mathrm{l})$ in women ${ }^{(27)}$. Finally, diabetes was defined as fasting glucose $\geq 126 \mathrm{mg} / \mathrm{dl}$ ( $\geq 7.0 \mathrm{mmol} / \mathrm{l})$, self-reported physician diagnosis or a self-reported use of hypoglycaemic treatment ${ }^{(28)}$.

\section{Estimation of the Framingham CHD risk score}

CHD risk was calculated using a previously validated calibration of the Framingham CHD Risk Score ${ }^{(29)}$. Sex-specific prediction algorithms that included age, cigarette smoking, blood pressure, diabetes and levels of HDL-cholesterol and LDL-cholesterol were computed. We defined participants with moderate to high risk of CHD when they had more than $10 \%$ risk in 10 years as was proposed in previous reports ${ }^{(24)}$.

\section{Statistical analysis}

We performed a descriptive analysis of the demographic and clinical variables by sex and quintiles of each beverage pattern. To assess differences between groups, we conducted a $\chi^{2}$ test for categorical variables and a Student's $t$ test or one-way ANOVA for continuous variables.

To estimate the association between beverage patterns and risk of $\mathrm{CHD}$, as well as other cardiovascular risk factors, we performed multivariable logistic regression models in order to estimate OR and 95\% CI, adjusting for potential confounding variables. The first model was adjusted for sex and age, whereas the second model was additionally adjusted for leisure time, physical activity, menopause, multivitamin supplements, medication use (treatment for diabetes, hypertension and hypercholesterolaemia) and aspirin use. Smoking and BMI were also included in the adjustment for the second model but only for blood lipids as a response variable. In the third model, we adjusted for energy intake and prudent pattern, meat/fish and refined foods consumption patterns. The fourth model was adjusted for smoking. In addition, an age-stratified analysis was performed ( $<45$ years, $45-56$ years and $>56$ years). The selection of the confounding variables was determined on the basis of previous scientific evidence. An additional sensitivity analysis with different parameters for total energy intake $(<2092$ and $>14644 \mathrm{~kJ} / \mathrm{d}(<500$ and $>3500 \mathrm{kcal} / \mathrm{d})$ ) was performed. Individuals who did not meet the assigned energy criteria were excluded from this analysis ( $n$ 336).

All $P$ values presented are two-tailed; a $P$ value $<0.05$ was considered statistically significant. All statistical analyses were performed using the STATA statistical software package version 14.0 (StataCorp LP).

\section{Results}

We identified four major beverage consumption patterns named according to the beverage groups that had positive high loadings (Table 1). Alcohol consumption was characterised by high alcohol intake and was explained by $17 \cdot 9 \%$ of the variance. The main beverages consumed in this pattern were beer, brandy and wine (data not shown). The coffee/tea pattern explained $16.6 \%$ of the variance and was defined by a high intake of coffee, tea and other non-dairy drinks, as well as low intake of high-fat beverages. The soft-drink pattern explained $15.9 \%$ of the variance and was characterised by a relatively high intake of sugar-sweetened carbonated drinks, and a low intake of homemade sweetened beverages, as well as low-energy drinks. The low-fat milk pattern explained $15.4 \%$ of the variance and was defined by a relatively high consumption of low-fat milk and a lower intake of industrialised sweetened

Table 1. Factor-loading matrix for patterns of beverage consumption*

\begin{tabular}{|c|c|c|c|c|}
\hline & Pattern 1 & Pattern 2 & Pattern 3 & Pattern 4 \\
\hline & Alcohol & Coffee/tea & Soft drinks & Low-fat milk \\
\hline High-fat milk beverages & & -0.8690 & & \\
\hline Low-fat milk beverages & & & & 0.9252 \\
\hline Homemade sweetened beverages & & & -0.9372 & \\
\hline Industrialised sweetened beverages & & & 0.5430 & -0.5011 \\
\hline Other sweetened beverages & & 0.7314 & & \\
\hline Alcoholic beverages & 0.8412 & & & \\
\hline Wine & 0.8408 & & & \\
\hline
\end{tabular}

* Factor loadings $>0.3$. 
beverages. Together, all four factors (beverage patterns) explained $65.8 \%$ of the total variance.

The study population was mainly composed of middle-aged participants ( 42.4 years old). Most participants were women $(71.6 \%)$, and the women in our study were less likely to be overweight, less likely to have a higher proportion of body fat, as well as a lower prevalence of low HDL-cholesterol, higher intake of low-fat beverages, lower dietary glycaemic load and a higher fibre and vitamin D consumption compared with men. In addition, women were less physically active during leisure time, smoked less, had a lower prevalence of lipid abnormalities, lower CHD risk and a lower soft-drink and alcohol consumption compared with men ( $P$ value $<0.05$ ) (data no shown).

Subjects in the highest quintile of the alcohol consumption pattern had a lower prevalence of obesity, lower body fat, HDL-cholesterol and diabetes, but also had a higher mean score of CHD risk in comparison with the lowest quintile. They were also more physically active during leisure time, were more likely to currently smoke, had lower dietary glycaemic load and higher vitamin D intake compared with subjects in the lowest quintile.
Low-fat milk consumption patterns yielded similar results to alcohol consumption patterns, except for the lower smoking prevalence and higher prevalence of diabetes. Participants in the top quintile of the coffee/tea pattern had higher prevalence of current smoking, had less prevalence of diabetes and less intake of saturated fats and vitamin D compared with participants in the bottom quintile. We observed that subjects in the highest quintile of soft-drink consumption pattern were older, had a higher prevalence of obesity, higher CHD risk, higher prevalence of low HDL-cholesterol and higher elevated LDL-cholesterol and TAG. These subjects were also less physically active during leisure time; had a higher prevalence of current smoking; had less energy intake, fibre intake and dietary glycaemic load; and also a higher intake of saturated fats compared with those in the lowest quintile (Table 2).

We observed a slight difference between adjusted and crude estimations. Subjects in the upper quintile of the alcohol consumption pattern had lower CHD risk (OR 0.56; $95 \%$ CI 0. 43, 0.74) and lower odds of low HDL-cholesterol (OR 0.74; $95 \%$ CI $0 \cdot 60,0 \cdot 91)$. The coffee/tea pattern is not significantly associated

Table 2. Characteristics of participants in the Health Worker Cohort Study by quintiles of beverage patterns

\begin{tabular}{|c|c|c|c|c|c|c|c|c|}
\hline & \multicolumn{2}{|c|}{ Alcohol pattern } & \multicolumn{2}{|c|}{ Coffee/tea pattern } & \multicolumn{2}{|c|}{ Soft-drink pattern } & \multicolumn{2}{|c|}{ Low-fat milk pattern } \\
\hline & Q1 & Q5 & Q1 & Q5 & Q1 & Q5 & Q1 & Q5 \\
\hline Sex (women) (\%) & $79 \cdot 6$ & $45 \cdot 1^{*}$ & $75 \cdot 8$ & $72 \cdot 8^{*}$ & $74 \cdot 7$ & $66 \cdot 2^{*}$ & $61 \cdot 5$ & $78 \cdot 8^{*}$ \\
\hline Age (years) $\dagger$ & $42 \cdot 5$ & $42 \cdot 4$ & 42.6 & $42 \cdot 8$ & 40.4 & $42 \cdot 0^{*}$ & 41.3 & $44.4^{*}$ \\
\hline BMI $\left(\mathrm{kg} / \mathrm{m}^{2}\right) \dagger$ & $27 \cdot 3$ & $26 \cdot 6^{\star}$ & $26 \cdot 4$ & $26 \cdot 6$ & $26 \cdot 2$ & $27 \cdot 4^{\star}$ & $27 \cdot 0$ & $26 \cdot 6^{\star}$ \\
\hline Overweight $\left(25.0-29.9 \mathrm{~kg} / \mathrm{m}^{2}\right)(\%)$ & 41.4 & 44.6 & 39.5 & $41 \cdot 3$ & 40.0 & 43.6 & $42 \cdot 6$ & $42 \cdot 1$ \\
\hline Obesity $\left(\geq 30.0 \mathrm{~kg} / \mathrm{m}^{2}\right)(\%)$ & $24 \cdot 0$ & $17 \cdot 2^{*}$ & $17 \cdot 8$ & $20 \cdot 6$ & $16 \cdot 6$ & $23 \cdot 6^{*}$ & $21 \cdot 8$ & $18 \cdot 2^{*}$ \\
\hline Body fat proportion $\dagger$ & 32.5 & $29 \cdot 1^{*}$ & $30 \cdot 9$ & $31 \cdot 0$ & $31 \cdot 1$ & 31.5 & $30 \cdot 3$ & $32 \cdot 0^{\star}$ \\
\hline Leisure time physical activity $(\mathrm{min} / \mathrm{d}) \dagger$ & 21.6 & $31.9^{*}$ & 24.3 & $25 \cdot 3$ & $28 \cdot 1$ & $23 \cdot 2^{*}$ & 23.7 & $26 \cdot 7^{\star}$ \\
\hline Smoking status (current) (\%) & $17 \cdot 9$ & $30 \cdot 8^{\star}$ & 14.9 & $22 \cdot 5^{\star}$ & $16 \cdot 6$ & $25 \cdot 6^{\star}$ & 27.9 & $13 \cdot 4^{\star}$ \\
\hline Total cholesterol $(\mathrm{mg} / \mathrm{dl}) \dagger \ddagger$ & 239.0 & $248 \cdot 0$ & $238 \cdot 0$ & $222 \cdot 0^{*}$ & 238.0 & $252 \cdot 0^{*}$ & 250.8 & $229 \cdot 5^{\star}$ \\
\hline High total cholesterol $(\geq 200 \mathrm{mg} / \mathrm{dl})(\%)$ & 51.5 & $57 \cdot 2^{*}$ & $69 \cdot 1$ & $43 \cdot 0^{*}$ & 54.0 & $56 \cdot 7$ & $55 \cdot 7$ & $50 \cdot 3^{*}$ \\
\hline HDL-cholesterol $(\mathrm{mg} / \mathrm{dl}) \dagger \ddagger$ & 38.4 & $39.6^{*}$ & $39 \cdot 3$ & $40 \cdot 2^{*}$ & 40.6 & $37.9^{\star}$ & $37 \cdot 3$ & $40 \cdot 7^{\star}$ \\
\hline Low HDL-cholesterol ( $<40 \mathrm{mg} / \mathrm{dl}$ for men, $<50 \mathrm{mg} / \mathrm{dl}$ in women) $(\%)$ & 84.9 & $73 \cdot 6^{*}$ & 81.0 & 79.0 & 77.9 & $82 \cdot 7^{\star}$ & 82.5 & $78.5^{\star}$ \\
\hline LDL-cholesterol (mg/dl)†‡ & $116 \cdot 0$ & $121 \cdot 0^{*}$ & $116 \cdot 3$ & 117.4 & $115 \cdot 0$ & $117 \cdot 0$ & $115 \cdot 7$ & $118 \cdot 4$ \\
\hline Elevated LDL-cholesterol ( $\geq 100 \mathrm{mg} / \mathrm{dl})(\%)$ & 66.9 & 69.9 & $66 \cdot 3$ & 67.5 & 62.9 & $68 \cdot 9^{*}$ & 66.9 & $67 \cdot 1$ \\
\hline TAG $(\mathrm{mg} / \mathrm{dl})^{\star} \ddagger$ & 153 & $170^{\star}$ & 157 & 156 & 152 & 159 & 161 & $153^{\star}$ \\
\hline Hypertriacylglycerolaemia ( $\geq 150 \mathrm{mg} / \mathrm{dl}$ ) (\%) & 41.7 & $47 \cdot 9^{\star}$ & 38.9 & $40 \cdot 2$ & 39.1 & $45 \cdot 8^{*}$ & $46 \cdot 0$ & $39 \cdot 6^{*}$ \\
\hline Diabetes (\%) & 10.5 & $5 \cdot 6^{\star}$ & $10 \cdot 2$ & $7 \cdot 5^{\star}$ & $6 \cdot 4$ & $8 \cdot 2$ & $5 \cdot 2$ & $10 \cdot 7^{\star}$ \\
\hline CHD risk† & 5.7 & $6 \cdot 4^{*}$ & $5 \cdot 6$ & $5 \cdot 6$ & 4.5 & $6 \cdot 0^{*}$ & $5 \cdot 8$ & 5.9 \\
\hline $\mathrm{CHD}$ risk (\%) & $20 \cdot 1$ & $19 \cdot 2$ & $19 \cdot 1$ & $17 \cdot 8$ & $12 \cdot 3$ & $19.8^{*}$ & $19 \cdot 1$ & 19.6 \\
\hline Total energy intake $(\mathrm{kJ} / \mathrm{d}) \dagger$ & 8761 & 9050 & 9598 & $8707^{*}$ & 10180 & $8761^{*}$ & 8937 & 8954 \\
\hline Total energy intake $(\mathrm{kcal} / \mathrm{d}) \dagger$ & 2094 & 2163 & 2294 & $2081^{*}$ & 2433 & $2094^{*}$ & 2136 & 2140 \\
\hline Carbohydrate intake (\% energy) $\dagger$ & $61 \cdot 6$ & $57 \cdot 1^{*}$ & $57 \cdot 6$ & $61.5^{\star}$ & $65 \cdot 7$ & $58 \cdot 7^{\star}$ & 60.5 & $60 \cdot 1$ \\
\hline Protein intake (\% energy) $\dagger$ & $14 \cdot 2$ & $14 \cdot 2$ & 14.9 & $14 \cdot 2^{*}$ & $12 \cdot 7$ & $14 \cdot 5^{\star}$ & 13.7 & $16 \cdot 2^{*}$ \\
\hline Polyunsaturated fat intake (\% energy) $\dagger$ & 4.5 & $4 \cdot 4^{*}$ & $4 \cdot 1$ & $4 \cdot 4^{*}$ & 3.8 & $4 \cdot 6^{*}$ & 4.5 & $4.2^{*}$ \\
\hline Saturated fat intake (\% energy) $\dagger$ & $8 \cdot 7$ & 8.7 & $11 \cdot 1$ & $8 \cdot 2^{\star}$ & 7.8 & $9 \cdot 0^{*}$ & 8.7 & $8 \cdot 3^{\star}$ \\
\hline Dietary fibre intake $(\mathrm{mg} / \mathrm{d}) \dagger$ & 28.5 & $27 \cdot 6$ & $29 \cdot 2$ & 28.6 & $32 \cdot 7$ & $26 \cdot 4^{*}$ & $26 \cdot 8$ & $29 \cdot 3^{*}$ \\
\hline Vitamin $D(\mu \mathrm{g} / \mathrm{d})$ & 4.7 & $5 \cdot 3^{*}$ & 8.6 & $5 \cdot 0^{*}$ & $5 \cdot 7$ & $5 \cdot 0^{*}$ & 3.9 & $8 \cdot 7^{\star}$ \\
\hline Glycaemic load $\dagger$ & $167 \cdot 2$ & $157 \cdot 9^{*}$ & $162 \cdot 5$ & $166 \cdot 6$ & $211 \cdot 7$ & $158 \cdot 2^{*}$ & $169 \cdot 4$ & $158 \cdot 6^{*}$ \\
\hline High-fat milk beverages $(\mathrm{ml} / \mathrm{d}) \dagger$ & 174.7 & $188 \cdot 1$ & $605 \cdot 3$ & $56 \cdot 5^{\star}$ & $220 \cdot 9$ & $199.5^{\star}$ & $182 \cdot 9$ & $190 \cdot 2$ \\
\hline Low-fat milk beverages $(\mathrm{ml} / \mathrm{d}) \dagger$ & $87 \cdot 6$ & $93 \cdot 0$ & $64 \cdot 2$ & $73 \cdot 1$ & $100 \cdot 7$ & $92 \cdot 7$ & $7 \cdot 7$ & $450 \cdot 6^{*}$ \\
\hline Homemade SSB $(\mathrm{ml} / \mathrm{d}) \dagger$ & 149.5 & $181 \cdot 2^{*}$ & 163.5 & $202 \cdot 7^{*}$ & $790 \cdot 1$ & $43.9^{*}$ & $142 \cdot 6$ & $176 \cdot 1^{*}$ \\
\hline Soft drinks $(\mathrm{ml} / \mathrm{d}) \dagger$ & 323.6 & $154 \cdot 3^{*}$ & $109 \cdot 9$ & $142 \cdot 1^{*}$ & $85 \cdot 3$ & $404 \cdot 9^{\star}$ & 439.9 & $74.4^{*}$ \\
\hline Low-energy drinks $(\mathrm{ml} / \mathrm{d}) \dagger$ & 54.9 & $20 \cdot 5^{\star}$ & 4.6 & $56 \cdot 2^{*}$ & $6 \cdot 3$ & $66 \cdot 5^{\star}$ & $2 \cdot 6$ & $59 \cdot 7^{\star}$ \\
\hline Other SSB $(\mathrm{ml} / \mathrm{d}) \dagger$ & $277 \cdot 2$ & $192 \cdot 8^{\star}$ & 61.8 & $489 \cdot 0^{*}$ & 183.4 & $159 \cdot 6^{*}$ & 198.5 & $119 \cdot 6^{*}$ \\
\hline Alcoholic beverages $(\mathrm{ml} / \mathrm{d}) \dagger$ & 4.0 & $158 \cdot 6^{*}$ & $26 \cdot 6$ & $41 \cdot 1^{\star}$ & 31.8 & $42 \cdot 9^{*}$ & 41.4 & $32 \cdot 4^{\star}$ \\
\hline Wine $(\mathrm{ml} / \mathrm{d}) \dagger$ & 0.3 & $16 \cdot 5^{\star}$ & $3 \cdot 3$ & $5 \cdot 7^{\star}$ & 3.6 & $2 \cdot 9^{\star}$ & $2 \cdot 7$ & $4.4^{*}$ \\
\hline
\end{tabular}

SSB, sugar-sweetened beverages.

${ }^{*} P$ values $<0.05$ from one-way ANOVA (continuous variables) or $x^{2}$ test (categorical variables) for quintile $1 \mathrm{v}$. quintile 5 .

$\dagger$ Mean values.

‡ To convert cholesterol in $\mathrm{mg} / \mathrm{dl}$ to $\mathrm{mmol} / \mathrm{l}$, multiply by 0.0259 . To convert TAG in $\mathrm{mg} / \mathrm{dl}$ to $\mathrm{mmol} / \mathrm{l}$, multiply by 0.0113 . 
with CHD (OR 0.81; 95\% CI 0.60, 1.09); however, subjects in the upper quintile of this pattern had lower odds of high serum cholesterol (OR 0.32; 95\% CI 0.26, 0.40). On the other hand, participants in the upper quintile of the soft-drink pattern had increased CHD risk (OR 1.53; 95\% CI 1.13, 2.07), increased odds of presenting high LDL-cholesterol (OR 1.20; $95 \%$ CI 1.01, 1.42) and were more likely to have lower HDL-cholesterol (OR 1.39; $95 \%$ CI $1 \cdot 13,1 \cdot 71)$ compared with those in the lowest quintile. In addition, participants in the upper quintile of the low-fat milk pattern had lower CHD risk (OR 0.66; $95 \%$ CI 0.48, 0.90) and lower odds for low HDL-cholesterol (OR 0.68; $95 \%$ CI 0.55, 0.84) compared with subjects in the lowest quintile (Tables 3 and 4). The results for all pattern groups are maintained despite the adjustment for BMI (model V). Results for the sensitivity analysis with different energy parameters are shown in the online Supplementary Table S1; the results of Tables 1, 3 and 4 remained similar.

Results for the age-stratified analysis of beverage patterns and CHD risk are presented in Fig. 1. Associations are not statistically significant across all age strata for alcohol, soft drinks or low-fat milk. This could be potentially explained by the limited sample size; however, the direction of the association shown in the analysis remains.

\section{Discussion}

By means of factor analysis, we identified four major beverage consumption patterns: 'Alcohol', 'Coffee/tea', 'Soft drinks' and 'Low-fat milk'. The Alcohol and Low-fat milk groups showed an inverse association with CHD, whereas the soft-drink pattern showed a positive association. Additional adjustment for BMI or total body fat proportion attenuated the association between beverage patterns and CHD; however, it remained significant (data not shown $)^{(30)}$. Obesity is part of the causal chain of these associations leading to chronic inflammation and increased cytokines by adipocytes ${ }^{(30,31)}$. Therefore, additional adjustment for BMI may be unnecessary.

Regarding alcohol intake among our population, the highest quintile of the Alcohol pattern represents an average of $1 \mathrm{cup} / \mathrm{d}$ for women and $2 \mathrm{cups} / \mathrm{d}$ for men. Our results are similar to those of the literature that observed an association between moderate alcohol consumption ( $1 \mathrm{cup} / \mathrm{d}$ for women and 2 cups/d for men) and lower CHD risk ${ }^{(9,10)}$. For example, the Health Professionals Follow-up Study reported that men who consumed alcohol daily, regardless of the type of drink, had a lower $\mathrm{CHD}$ risk $^{(32)}$. The Women's Health Initiative Observational Study showed that moderate alcohol intake is inversely associated with CHD risk ${ }^{(33)}$. In a recent review paper combining results from eighty-four observational studies, moderate alcohol drinkers were reported to have reduced risk of CVD outcomes compared with non-drinkers, although heavy drinkers had the highest CVD risk of all ${ }^{(34)}$. With regard to mechanisms underlying the effects of alcohol on lipid metabolism, alcohol consumption has been shown to increase the activity of lipoprotein lipase and decrease the activity of cholesterol ester transfer protein, resulting in the elevation of HDL-cholesterol ${ }^{(35)}$.

With respect to the SSB intake, previous studies showed that SSB consumption increases CHD risk ${ }^{(12,13,24,36)}$. A meta-analysis showed increased CHD risk in the upper category of SSB intake compared with the lowest category (relative risk $(\mathrm{RR})=1 \cdot 17$; $95 \%$ CI 1.07, 1.28) ${ }^{(12)}$. The Nurses' Health Study reported that women with a daily intake of $\geq 1$ drink had increased CHD risk compared with women who did not drink $\mathrm{SSB}^{(13)}$. Studies evaluating complete dietary patterns and CHD showed that the pattern typified by a high intake of SSB is associated with increased CVD risk ${ }^{(24,36)}$. A longitudinal study with data from our cohort (HWCS) shows that subjects in the highest quintile of the 'refined foods' pattern characterised by SSB have an increased risk of CVD, compared with those in the lowest quintile $(\mathrm{RR}=2 \cdot 98 ; 95 \% \mathrm{CI} 1 \cdot 46,6 \cdot 10)^{(24)}$. Longitudinal and cross-sectional studies have observed similar results for HDLcholesterol. For example, Denova-Gutiérrez et al. ${ }^{(15)}$ showed that individuals with a consumption of $\geq 1$ serving/d of SSB were two times more likely to have low HDL-cholesterol than those with zero consumption. Dhingra et $a l^{(37)}$ found that $\geq 1$ portion of soft drinks per day increases the incidence of low HDL-cholesterol by $38 \%$ compared with subjects who do not consume soft drinks. Nevertheless, there are some studies ${ }^{(38,39)}$ that have found no association between SSB consumption and CHD, such as a systematic review conducted by Hoare et $a l .{ }^{(38)}$ in which they claim that there is consistent evidence that SSB consumption has adverse associations with weight, but there are insufficient data to assess relationships with cardiometabolic outcomes.

The association between coffee or tea consumption and CHD or lipid profiles is still not well studied, and previous epidemiological study results draw different conclusions ${ }^{(40-47)}$. Previous studies reported that coffee or tea consumption is inversely associated with CHD or serum lipids ${ }^{(40,41)}$. On the other hand, some studies reported no relation or higher risk between coffee or tea consumption and the CHD or lipid profile ${ }^{(41-43)}$. We observed an inverse association between beverage pattern characterised by Coffee/tea with low HDL-cholesterol and total cholesterol. Possible biological mechanisms may explain these associations and have something to do with the antioxidants found in coffee and tea, such as vitamin C, several B vitamins, $\mathrm{Mg}, \mathrm{K}, \mathrm{Mn}$ and fluoride ${ }^{(44,45)}$. In addition, these drinks contain polyphenols, which have a beneficial effect on cholesterol levels. Studies in rats suggest that polyphenols limit cholesterol absorption and promote efflux of cholesterol accumulated in cells, as well as inhibit LDL-cholesterol oxidation in vivo owing to increasing serum concentrations of HDL-cholesterol ${ }^{(37,48)}$.

One outstanding result of our study is the inverse association between the low-fat milk pattern and CHD that is consistent with the results of other prospective cohort studies ${ }^{(49,50)}$. Milk is rich in minerals ( $\mathrm{Ca}, \mathrm{K}$ and $\mathrm{Mg}$ ), protein (casein and whey) and vitamins (riboflavin, vitamin $\mathrm{D}$ and vitamin $\mathrm{B}_{12}$ ) that can exert beneficial effects on $\mathrm{CVD}^{(51)}$. For example, two individual metaanalyses have reported an inverse relationship between higher Ca intake and reduced blood pressure ${ }^{(52,53)}$. In addition, one of the established properties of milk fat relative to polyunsaturated oils is the increase in concentration of HDL-cholesterol, which is associated with protection from heart disease ${ }^{(54)}$.

In our study, we observed different CHD risk scores for men and women ( $7 \cdot 7$ and $4 \cdot 7$, respectively, data no shown). This result is similar to those obtained in the National Health and Nutrition Examination Survey) (8.6 in men and 4.7 in women) and those obtained by Karim et al. with data of the B-Vitamin 
Table 3. Cardiovascular risk factors according to alcohol and coffee/tea patterns (Odds ratios and $95 \%$ confidence intervals)

\begin{tabular}{|c|c|c|c|c|c|c|c|c|c|c|c|c|c|c|c|c|c|c|c|c|}
\hline & \multicolumn{10}{|c|}{ Alcohol pattern } & \multicolumn{10}{|c|}{ Coffee/tea pattern } \\
\hline & \multirow[b]{2}{*}{ Q1 } & \multicolumn{2}{|r|}{ Q2 } & \multicolumn{2}{|r|}{ Q3 } & \multicolumn{2}{|r|}{ Q4 } & \multicolumn{2}{|r|}{ Q5 } & \multirow[b]{2}{*}{$P$} & \multirow[b]{2}{*}{ Q1 } & \multicolumn{2}{|r|}{ Q2 } & \multicolumn{2}{|r|}{ Q3 } & \multicolumn{2}{|r|}{ Q4 } & \multicolumn{2}{|r|}{ Q5 } & \multirow[b]{2}{*}{$P$} \\
\hline & & OR & $95 \% \mathrm{Cl}$ & OR & $95 \% \mathrm{Cl}$ & OR & $95 \% \mathrm{Cl}$ & OR & $95 \% \mathrm{Cl}$ & & & OR & $95 \% \mathrm{Cl}$ & OR & $95 \% \mathrm{Cl}$ & OR & $95 \% \mathrm{Cl}$ & OR & $95 \% \mathrm{Cl}$ & \\
\hline \multicolumn{21}{|c|}{ Risk of $\mathrm{CHD}$ ( $\geq 10$ in 10 years) } \\
\hline Model I* & 1.0 & 0.77 & $0.59,1.00$ & 0.70 & $0.54,0.92$ & 0.72 & $0.55,0.93$ & 0.59 & $0.45,0.77$ & 0.001 & 1.0 & 1.04 & $0.79,1.35$ & 0.94 & $0.72,1.22$ & 1.03 & $0.79,1.34$ & 1.02 & $0.79,1.32$ & 0.895 \\
\hline Model II $†$ & 1.0 & 0.75 & $0.58,0.99$ & 0.69 & $0.53,0.91$ & 0.71 & $0.55,0.93$ & 0.61 & $0.47,0.80$ & 0.001 & 1.0 & 1.03 & $0.79,1.35$ & 0.95 & $0.72,1.24$ & 1.01 & $0.78,1.32$ & 1.03 & $0.80,1.34$ & 0.861 \\
\hline Model III‡ & 1.0 & 0.78 & $0.59,1.03$ & 0.73 & $0.56,0.97$ & 0.73 & $0.55,0.95$ & 0.61 & $0.46,0.80$ & 0.001 & 1.0 & 0.97 & $0.76,1.31$ & 0.88 & $0.66,1 \cdot 16$ & 0.90 & $0.68,1.20$ & 0.92 & $0.69,1.22$ & 0.424 \\
\hline Model IV§ & 1.0 & 0.80 & $0.60,1.06$ & 0.81 & $0.61,1.08$ & 0.75 & $0.57,0.99$ & 0.60 & $0.45,0.79$ & 0.001 & 1.0 & 0.94 & $0.71,1.25$ & 0.82 & $0.62,1 \cdot 10$ & 0.79 & $0.59,1.07$ & 0.81 & $0.60,1 \cdot 10$ & 0.105 \\
\hline \multicolumn{21}{|c|}{ High total cholesterol $(\geq 200 \mathrm{mg} / \mathrm{dl})$} \\
\hline Model I & 1.0 & 1.33 & $1.14,1.55$ & 1.38 & $1 \cdot 18,1.61$ & $1 \cdot 17$ & $0.99,1.36$ & 1.09 & $0.93,1.28$ & 0.654 & 1.0 & 0.80 & $0.68,0.94$ & 0.47 & $0.40,0.55$ & 0.48 & $0.41,0.56$ & 0.34 & $0.29,0.40$ & $<0.001$ \\
\hline Model II & 1.0 & 1.33 & $1.14,1.56$ & 1.39 & $1.18,1.61$ & $1 \cdot 16$ & $0.99,1.35$ & 1.07 & $0.91,1.25$ & 0.857 & 1.0 & 0.80 & $0.68,0.94$ & 0.46 & $0.40,0.55$ & 0.47 & $0.40,0.57$ & 0.33 & $0.28,0.39$ & $<0.001$ \\
\hline Model III & 1.0 & 1.29 & $1.05,1.59$ & 1.22 & $0.99,1.49$ & $1 \cdot 14$ & $0.93,1.39$ & 0.91 & $0.74,1.13$ & 0.283 & 1.0 & 0.54 & $0.43,0.67$ & 0.28 & $0.23,0.35$ & 0.31 & $0.24,0.39$ & 0.32 & $0.26,0.39$ & $<0.001$ \\
\hline Model IV & 1.0 & 1.28 & $1.04,1.57$ & 1.21 & $0.99,1.48$ & $1 \cdot 14$ & $0.93,1.40$ & 0.92 & $0.75,1.14$ & 0.389 & 1.0 & 0.54 & $0.44,0.67$ & 0.28 & $0.23,0.35$ & 0.32 & $0.26,0.39$ & 0.32 & $0.26,0.40$ & $<0.001$ \\
\hline \multicolumn{21}{|c|}{ Low HDL-cholesterol ( $<40 \mathrm{mg} / \mathrm{dl}$ for men and $<50 \mathrm{mg} / \mathrm{dl}$ in women) } \\
\hline Model I & 1.0 & 0.78 & $0.64,0.97$ & 0.73 & $0.59,0.90$ & 0.66 & $0.54,0.81$ & 0.69 & $0.57,0.85$ & $<0.001$ & 1.0 & 1.02 & $0.84,1.24$ & 0.94 & $0.77,1.14$ & 0.98 & 0.8 & 0.87 & 1.06 & 0.169 \\
\hline Model II & 1.0 & 0.79 & $0.64,0.97$ & 0.73 & $0.59,0.90$ & 0.67 & $0.55,0.82$ & 0.70 & $0.57,0.86$ & $<0.001$ & 1.0 & 1.02 & $0.84,1.24$ & 0.94 & $0.78,1.15$ & 0.98 & 19 & 0.87 & $0.72,1.06$ & 0.146 \\
\hline Model III & 1.0 & 0.80 & $0.65,0.99$ & 0.75 & $0.61,0.92$ & 0.69 & $0.57,0.85$ & 0.71 & $0.58,0.88$ & 0.001 & 1.0 & 1.01 & $0.83,1.23$ & 0.95 & $0.78,1.16$ & 1.00 & $0.82,1.21$ & 0.91 & $0.75,1.11$ & 0.382 \\
\hline Model IV & 1.0 & 0.82 & $0.66,1.02$ & 0.77 & $0.63,0.96$ & 0.73 & $0.59,0.89$ & 0.74 & $0.60,0.91$ & 0.003 & 1.0 & 0.99 & $0.81,1.21$ & 0.92 & $0.76,1 \cdot 12$ & 0.94 & $0.77,1.15$ & 0.90 & $0.73,1 \cdot 10$ & 0.249 \\
\hline \multicolumn{21}{|c|}{ High LDL-cholesterol ( $\geq 100 \mathrm{mg} / \mathrm{dl})$} \\
\hline Model I & 1.0 & 0.92 & $0.78,1.08$ & 0.92 & $0.78,1.08$ & 0.97 & 0.82 & 1.11 & 0.93 & 0.232 & 1.0 & 1.01 & 19 & 1.02 & $0.86,1.20$ & 0.98 & & 1.05 & .24 & 0.732 \\
\hline Model II & 1.0 & 0.92 & $0.78,1.08$ & 0.93 & $0.79,1.09$ & 0.97 & $0.82,1 \cdot 15$ & 1.11 & $0.93,1.32$ & 0.214 & 1.0 & 1.00 & $0.85,1 \cdot 18$ & 1.02 & $0.87,1.21$ & 0.98 & $0.83,1 \cdot 16$ & 1.06 & $0.89,1.25$ & 0.649 \\
\hline Model III & $1 \cdot 0$ & 0.92 & $0.78,1.08$ & 0.92 & $0.78,1.09$ & 0.97 & $0.82,1 \cdot 15$ & 1.11 & $0.93,1.32$ & 0.247 & 1.0 & 1.00 & $0.85,1.18$ & 1.02 & $0.86,1.20$ & 0.98 & $0.83,1 \cdot 16$ & 1.07 & $0.90,1.27$ & 0.55 \\
\hline Model IV & 1.0 & 0.93 & $0.79,1 \cdot 10$ & 0.94 & $0.80,1.11$ & 0.98 & $0.83,1.16$ & 1.11 & $0.93,1.32$ & 0.25 & 1.0 & 0.99 & $0.84,1.17$ & 1.01 & $0.85,1.19$ & 0.96 & $0.82,1.14$ & 1.04 & $0.88,1.24$ & 0.789 \\
\hline \multicolumn{21}{|c|}{ Hypertriacylglycerolaemia $(\geq 150 \mathrm{mg} / \mathrm{dl}$ ) } \\
\hline Model I & 1.0 & 0.88 & $0.75,1.03$ & 0.93 & 0 & 8 & S & 0.91 & 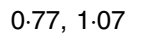 & 0.322 & 1.0 & $1 \cdot 2$ & 2 & 1.04 & 0 & 1.23 & 45 & 1.00 & 18 & 0.911 \\
\hline Model II & 1.0 & 0.88 & $0.74,1.03$ & 0.94 & $0.80,1 \cdot 11$ & 0.89 & $0.76,1.05$ & 0.94 & $0.79,1.11$ & 0.542 & 1.0 & 1.21 & $1.03,1.43$ & 1.05 & $0.90,1.24$ & 1.02 & 1.46 & 1.01 & $0.89,1 \cdot 19$ & 0.823 \\
\hline Model III & 1.0 & 0.87 & $0.74,1.02$ & 0.95 & $0.80,1 \cdot 12$ & 0.92 & $0.78,1.08$ & 0.98 & $0.83,1.16$ & 0.989 & 1.0 & 1.23 & $1.04,1.44$ & 1.08 & $0.92,1.23$ & 1.28 & $1.08,1.50$ & 1.05 & $0.89,1.25$ & 0.412 \\
\hline Model IV & 1.0 & 0.92 & $0.77,1.08$ & 1.02 & $0.86,1.20$ & 0.98 & $0.83,1.15$ & 1.02 & $0.85,1.21$ & 0.661 & 1.0 & 1.20 & $1.01,1.41$ & 1.04 & $0.88,1.23$ & $1 \cdot 19$ & $1.01,1.41$ & 1.00 & $0.84,1.19$ & 0.986 \\
\hline
\end{tabular}

* Model I: adjustment for sex; age (years).

† Model II: additional adjustment for leisure time physical activity ( $\geq 30 \mathrm{~min} / \mathrm{d}$ ); menopause; use of multivitamin supplements; medication use (treatment for diabetes, hypertension and hypercholesterolaemia); and aspirin use. ¥ Model III: additional adjustment for intakes of total energy (quintiles); prudent pattern (quintiles); meat/fish pattern (quintiles); and refined food pattern (quintiles).

$\S$ Model IV: additional adjustment for BMI (normal, overweight and obesity) and smoking status. 
Table 4. Cardiovascular risk factors according to soft-drink and low-fat milk patterns (Odds ratios and $95 \%$ confidence intervals)

\begin{tabular}{|c|c|c|c|c|c|c|c|c|c|c|c|c|c|c|c|c|c|c|c|c|}
\hline & \multicolumn{10}{|c|}{ Soft-drink pattern } & \multicolumn{10}{|c|}{ Low-fat milk pattern } \\
\hline & \multirow[b]{2}{*}{ Q1 } & \multicolumn{2}{|r|}{ Q2 } & \multicolumn{2}{|r|}{ Q3 } & \multicolumn{2}{|r|}{ Q4 } & \multicolumn{2}{|r|}{ Q5 } & \multirow[b]{2}{*}{$P$} & \multirow[b]{2}{*}{ Q1 } & \multicolumn{2}{|r|}{ Q2 } & \multicolumn{2}{|r|}{ Q3 } & \multicolumn{2}{|r|}{ Q4 } & \multicolumn{2}{|r|}{ Q5 } & \multirow[b]{2}{*}{$P$} \\
\hline & & OR & $95 \% \mathrm{Cl}$ & OR & $95 \% \mathrm{Cl}$ & OR & $95 \% \mathrm{Cl}$ & OR & $95 \% \mathrm{Cl}$ & & & OR & $95 \% \mathrm{Cl}$ & OR & $95 \% \mathrm{Cl}$ & OR & $95 \% \mathrm{Cl}$ & OR & $95 \% \mathrm{Cl}$ & \\
\hline \multicolumn{21}{|c|}{ Risk of $\mathrm{CHD}$ ( $\geq 10$ in 10 years) } \\
\hline Model I* & 1.0 & 1.23 & $0.92,1.63$ & $1 \cdot 10$ & $0.83,1.45$ & 1.35 & $1.03,1.77$ & 1.51 & $1.14,1.99$ & 0.003 & 1.0 & 0.72 & $0.55,0.93$ & 0.67 & $0.51,0.87$ & 0.76 & $0.51,0.87$ & 0.61 & $0.47,0.79$ & 0.002 \\
\hline Model II† & $1 \cdot 0$ & $1 \cdot 24$ & $0.93,1.65$ & $1 \cdot 12$ & $0.85,1.49$ & 1.33 & $1.01,1.75$ & 1.54 & $1 \cdot 16,2 \cdot 04$ & 0.003 & 1.0 & 0.72 & $0.55,0.94$ & 0.65 & $0.49,0.85$ & 0.73 & $0.56,0.96$ & 0.58 & $0.44,0.76$ & $<0.001$ \\
\hline Model III‡ & 1.0 & $1 \cdot 34$ & $0.99,1.80$ & 1.23 & $0.92,1.66$ & 1.52 & $1 \cdot 13,2.05$ & 1.65 & $1 \cdot 22,2 \cdot 21$ & 0.001 & 1.0 & 0.71 & $0.55,0.93$ & 0.64 & $0.48,0.85$ & 0.72 & $0.54,0.96$ & 0.58 & $0.43,0.79$ & 0.003 \\
\hline Model IV§ & 1.0 & $1 \cdot 32$ & $0.98,1.79$ & $1 \cdot 15$ & $0.85,1.57$ & 1.47 & $1.08,2.00$ & 1.43 & $1.06,1.94$ & 0.02 & 1.0 & 0.79 & $0.60 \quad 1.04$ & 0.75 & $0.56,1.01$ & 0.79 & $0.59,1.06$ & 0.68 & $0.50,0.93$ & 0.42 \\
\hline \multicolumn{21}{|c|}{ High total cholesterol ( $\geq 200 \mathrm{mg} / \mathrm{dl})$} \\
\hline Model I & $1 \cdot 0$ & $1 \cdot 20$ & $1.03,1.40$ & 1.28 & $1.10,1.49$ & 1.06 & $0.91,1.24$ & 1.11 & 0.95 & 0.645 & 1.0 & $1 \cdot 11$ & 0.9 & 1.45 & 1.24, & 1.08 & 0.9 & 0.89 & $0.77,1.04$ & 0.147 \\
\hline Model II & $1 \cdot 0$ & $1 \cdot 20$ & $1.02,1.40$ & $1 \cdot 28$ & $1.09,1.49$ & 1.07 & $0.92,1.25$ & 1.11 & $0.95,1.29$ & 0.607 & 1.0 & $1 \cdot 11$ & $0.95,1.29$ & 1.46 & $1 \cdot 25,1 \cdot 71$ & 1.07 & $0.92,1.25$ & 0.89 & $0.77,1.04$ & 0.135 \\
\hline Model III & 1.0 & $2 \cdot 04$ & $1.66,2.52$ & 2.55 & $2.07,3.14$ & $2 \cdot 66$ & $2 \cdot 15,3 \cdot 29$ & 1.88 & $1.53,2.32$ & $<0.001$ & 1.0 & 1.28 & $1.04,1.57$ & 1.76 & $1.43,2 \cdot 17$ & $1 \cdot 17$ & $0.95,1.43$ & $1 \cdot 16$ & $0.94,1.44$ & 0.422 \\
\hline Model IV & $1 \cdot 0$ & 2.06 & $1.67,2.53$ & $2 \cdot 57$ & $2 \cdot 09,3 \cdot 16$ & $2 \cdot 68$ & $2 \cdot 17,3.31$ & 1.93 & $1 \cdot 56,2 \cdot 38$ & $<0.001$ & 1.0 & 1.28 & $1.04,1.57$ & 1.74 & $1.41,2 \cdot 15$ & $1 \cdot 15$ & $0.94,1.43$ & 1.15 & $0.93,1.42$ & 0.506 \\
\hline \multicolumn{21}{|c|}{ Low HDL-cholesterol ( $<40 \mathrm{mg} / \mathrm{dl}$ for men and $<50 \mathrm{mg} / \mathrm{dl}$ in women) } \\
\hline Model I & $1 \cdot 0$ & $1 \cdot 20$ & $0.99,1.45$ & 1.00 & $0.83,1 \cdot 21$ & $1 \cdot 14$ & $0.94,1.38$ & 1.50 & $1 \cdot 24,1 \cdot 83$ & 0.001 & 1.0 & 0.85 & $0.69,1.04$ & 0.61 & $0.50,0.74$ & 0.67 & $0.55,0.82$ & 0.61 & $0.50,0.75$ & $<0.001$ \\
\hline Model II & 1.0 & $1 \cdot 20$ & 0.99 & 1.01 & $0.84,1.22$ & $1 \cdot 15$ & $0.95,1.39$ & 1.51 & $1 \cdot 24,1.84$ & 0.001 & 1.0 & 0.85 & & 0.60 & $0.50,0.74$ & 0.67 & & 0.61 & .75 & $<0.001$ \\
\hline Model III & 1.0 & $1 \cdot 24$ & $1.02,1.51$ & 1.03 & $0.86,1.25$ & $1 \cdot 19$ & $0.98,1.45$ & 1.46 & $1.20,1.79$ & 0.002 & 1.0 & 0.88 & $0.72,1.08$ & 0.63 & $0.52,0.77$ & 0.72 & $0.59,0.89$ & 0.68 & $0.55,0.83$ & $<0.001$ \\
\hline Model IV & $1 \cdot 0$ & 1.26 & $1.03,1.53$ & 1.04 & $0.86,1 \cdot 26$ & $1 \cdot 18$ & $0.97,1.43$ & 1.39 & $1 \cdot 13,1.07$ & 0.001 & 1.0 & 0.90 & $0.73,1.11$ & 0.65 & $0.53,0.79$ & 0.72 & $0.58,0.88$ & 0.68 & $0.55,0.84$ & $<0.001$ \\
\hline \multicolumn{21}{|c|}{ High LDL-cholesterol ( $\geq 100$ mg/dl) } \\
\hline Model I & 1.0 & $1 \cdot 15$ & $0.98,1.36$ & 1.06 & 0.90 & 1.07 & & 1.23 & 1 & & 1.0 & 1.02 & & 0.92 & & 0.95 & & 0.93 & 10 & 0.251 \\
\hline Model II & 1.0 & $1 \cdot 15$ & $0.98,1.36$ & 1.05 & $0.89,1.24$ & 1.06 & $0.90,1.25$ & 1.23 & $1.04,1.45$ & 0.084 & 1.0 & 1.03 & $0.87,1.21$ & 0.93 & $0.79,1 \cdot 10$ & 0.95 & $0.81,1 \cdot 13$ & 0.93 & $0.79,1 \cdot 10$ & 0.265 \\
\hline Model III & $1 \cdot 0$ & $1 \cdot 16$ & $0.99,1.37$ & 1.06 & $0.90,1.25$ & 1.08 & $0.91,1.27$ & 1.23 & $1.04,1.46$ & 0.076 & 1.0 & 1.03 & $0.87,1 \cdot 21$ & 0.93 & $0 \cdot 78,1 \cdot 10$ & 0.96 & $0.81,1 \cdot 13$ & 0.94 & $0.79,1 \cdot 12$ & 0.332 \\
\hline Model IV & 1.0 & $1 \cdot 16$ & $0.98,1.37$ & 1.06 & $0.89,1.25$ & 1.07 & $0.90,1.26$ & 1.20 & $1.01,1.42$ & 0.145 & 1.0 & 1.04 & $0.88,1.23$ & 0.95 & $0.80,1 \cdot 13$ & 0.97 & $0.82,1 \cdot 15$ & 0.96 & $0.81,1 \cdot 15$ & 0.473 \\
\hline \multicolumn{21}{|c|}{ Hypertriacylglycerolaemia ( $\geq 150 \mathrm{mg} / \mathrm{dl})$} \\
\hline Model I & 1.0 & 1.01 & $0.86,1.19$ & 0.93 & s & 0.97 & 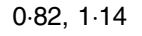 & $1 \cdot 16$ & & 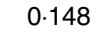 & 1.0 & 0.8 & $r$ & 0.90 & 0 . & 0.82 & & 0.81 & & $0 . c$ \\
\hline Model II & 1.0 & 1.01 & $0.86,1.19$ & 0.93 & $0.79,1.09$ & 0.95 & $0.81,1 \cdot 12$ & 1.15 & $0.98,1.35$ & 0.213 & 1.0 & 0.89 & $0.76,1.05$ & 0.91 & $0.78,1.07$ & 0.82 & .97 & 0.81 & .95 & 0.006 \\
\hline Model III & $1 \cdot 0$ & 1.02 & $0.87,1.20$ & 0.94 & $0 \cdot 79,1 \cdot 11$ & 0.98 & $0.83,1.16$ & $1 \cdot 16$ & $0.98,1.37$ & 0.164 & 1.0 & 0.90 & $0.77,1.06$ & 0.92 & $0.78,1.09$ & 0.85 & $0.72,1 \cdot 01$ & 0.85 & $0.72,1.01$ & 0.057 \\
\hline Model IV & 1.0 & 1.01 & $0.86,1.20$ & 0.92 & $0.77,1.09$ & 0.95 & $0.80,1.13$ & 1.05 & $0.89,1.25$ & 0.827 & 1.0 & 0.95 & $0.80,1.12$ & 1.00 & $0.84,1 \cdot 18$ & 0.88 & $0.74,1.04$ & 0.91 & $0.76,1.08$ & 0.184 \\
\hline
\end{tabular}

* Model I: adjustment for sex; age (years).

† Model II: additional adjustment for leisure time physical activity ( $\geq 30 \mathrm{~min} / \mathrm{d}$ ); menopause; use of multivitamin supplements; medication use (treatment for diabetes, hypertension and hypercholesterolaemia); and aspirin use. ‡ Model III: additional adjustment for intakes of total energy (quintiles); prudent pattern (quintiles); meat/fish pattern (quintiles); and refined food pattern (quintiles).

$\S$ Model IV: additional adjustment for BMI (normal, overweight and obesity) and smoking status. 
Beverage consumption patterns (total and by age group)

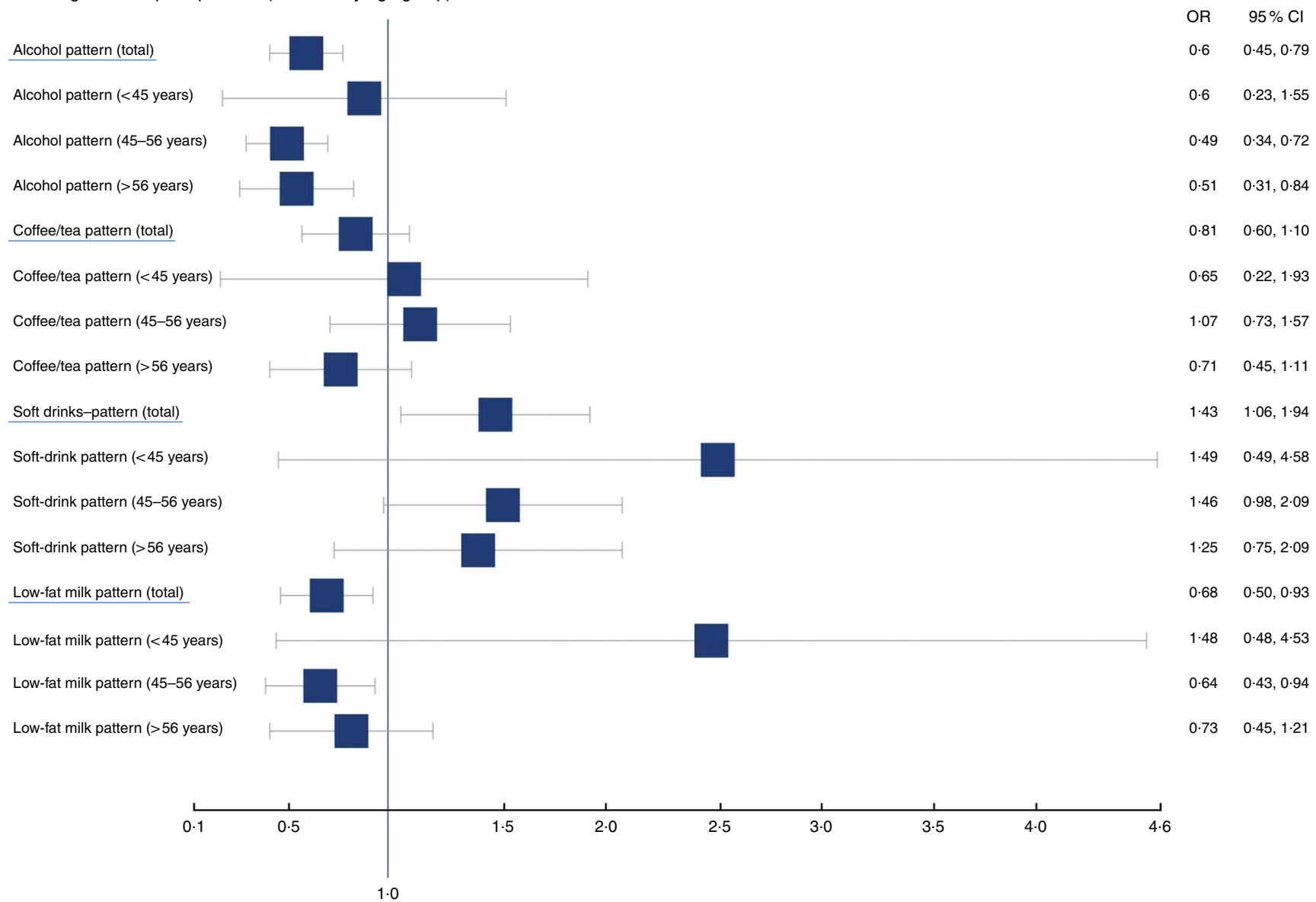

Fig. 1. OR of cardiovascular risk factors and patterns of beverage consumption, age-stratified analysis.

Atherosclerosis Intervention Trial (13.0 men and 6.0 women, respectively, $P<0 \cdot 001)^{(53,54)}$. Sex is one of the main risk factors for CHD owing to exposure to endogenous oestrogens during the fertile period and, at this stage, the rate of CHD events is low ${ }^{(55)}$. When we stratified by sex, we observed that the association is stronger in menopausal women, OR 1.79 (95\% CI 1.19, 2.70), and non-menopausal women, OR 1.21 (95\% CI $0.49,3.03)$. On the other hand, for men this association was NS (OR 1.11; $95 \% \mathrm{CI}$ $0.70,1.77)$, which can be attributed to a small sample size. We also explored the association for a $\geq 20 \%$ CHD risk and observed an OR of 1.35 (95\% CI $0.65,2.80)$ for women in the highest quintile of the soft-drink pattern and 1.96 (95\% CI 0.84, 4.56) for men when compared with subjects in the lowest quintile.

There are some limitations that must be considered for the interpretation of our results. First, given the cross-sectional nature of this analysis, we cannot infer that observed associations are causal. Despite the fact that FFQ is a standard method for collecting information on dietary intake, estimates derived from this instrument are not error-free. Nevertheless, our questionnaire had been previously validated and a recently published article by DenovaGutiérrez et al. used a similar FFQ instrument, which found reasonable interclass correlation for some beverage groups (e.g. 0.29 for alcoholic beverages, 0.47 for sweetened beverages and 0.64 for soft drinks) ${ }^{(56)}$. Another limitation is that we did not consider water consumption as part of a beverage group to be included in the analysis as we excluded the water-related question in the FFQ owing to misinterpretation. Factor analysis has some limitations related to methodological variation, including the number of food groups used in factor analysis, the number of factors and the rotation employed. However, the techniques we used are empirically derived and are, therefore, not limited by prior knowledge. Another consideration is that beverage intake can be correlated with other risk factors that were not measured in this study. Even though we controlled for all potential confounding factors, residual confounding by unmeasured or imperfectly measured factors may still exist. How representative our findings are is limited by the fact that the participants and their families are health professionals who may practise different lifestyle behaviours that vary from those of the general population. However, we believe our population is representative of the urban population of central Mexico. In this same sense, we cannot rule out the possibility of reverse causality as subjects with a chronic disease (e.g. diabetes) were able to modify their beverage consumption pattern because of their knowledge of the disease or some medical recommendation.

To date, there are no studies that document the association between beverage consumption patterns and CHD. Analysing beverage consumption patterns allows for easy interpretation and a more comprehensive assessment of beverage intake. It can also be translated into dietary recommendations ${ }^{(18)}$. Our findings are relevant because we analysed each beverage group 
separately, which enabled us to be able to observe independent effects of certain types of beverages on CHD.

In conclusion, among Mexican adults, Alcohol and Low-fat milk patterns were inversely associated with $\mathrm{CHD}$, whereas the soft-drink pattern was positively associated. Our data suggest possible dietary recommendations for preventing CHD in Mexican adults; however, further longitudinal studies in various populations following different beverage patterns are required to confirm these results.

\section{Acknowledgements}

The present study was supported by Consejo Nacional de Ciencia y Tecnología CONACYT (grant no. 262233).

B. R.-P. and J. S. were involved in the conception and design of the study; B. R.-P. and P. M.-A. participated in the statistical analysis and interpreted the final data; B. R.-P., P. M.-A., L. T.-I., P. R., R. H.-L., E. B., L. L.-M., E. H., E. D.-G., M. F., E. S.-M. and J. S. drafted the manuscript; all authors reviewed and commented on the manuscript; all authors read and approved the final manuscript.

The authors declare that there are no conflicts of interest

\section{Supplementary material}

For supplementary material/s referred to in this article, please visit https://doi.org/10.1017/S0007114518001411

\section{References}

1. Roth GA, Huffman MD, Moran AE, et al. (2015) Global and regional patterns in cardiovascular mortality from 1990 to 2013. Circulation 132, 1667-1678

2. World Health Organization (2014) Global status report on noncommunicable diseases, 2014. http://www.who.int/nmh/ publications/ncd-status-report-2014/en/ (accessed August 2016).

3. Institute for Health Metrics and Evaluation (2013) Global burden of disease in Mexico, 2013. http://www.healthdata. org/mexico (accessed August 2016).

4. Eaton CB (2005) Traditional and emerging risk factors for cardiovascular disease. Prim Care 32, 963-976.

5. Gutiérrez JP, Rivera-Dommarco J, Shamah-Levy T, et al. (2012) Encuesta Nacional de Salud y Nutrición 2012. Resultados Nacionales. Cuernavaca: Instituto Nacional de Salud Pública.

6. Kromhout D, Menotti A, Kesteloot H, et al. (2002) Prevention of coronary heart disease by diet and lifestyle: evidence from prospective cross-cultural, cohort, and intervention studies. Circulation 105, 893-898.

7. Zhang Y \& Hu G (2012) Dietary pattern, lifestyle factors, and cardiovascular diseases. Curr Nutr Rep 1, 64-72.

8. Djoussé L, Lee IM, Buring JE, et al. (2009) Alcohol consumption and risk of cardiovascular disease and death in women: potential mediating mechanisms. Circulation 120, 237-244.

9. Zhang X-Y, Shu L, Si C-J, et al. (2015) Dietary patterns, alcohol consumption and risk of coronary heart disease in adults: a meta-analysis. Nutrients 7, 6582-6605.

10. Zheng YL, Lian F, Shi Q, et al. (2015) Alcohol intake and associated risk of major cardiovascular outcomes in women compared with men: a systematic review and meta-analysis of prospective observational studies. BMC Public Health 15, 773.
11. O'Keefe JH, Bybee KA \& Lavie CJ (2007) Alcohol and cardiovascular health: the razor-sharp double-edged sword. $J \mathrm{Am}$ Coll Cardiol 50, 1009-1014.

12. Huang C, Huang J, Tian Y, et al. (2014) Sugar sweetened beverages consumption and risk of coronary heart disease: a meta-analysis of prospective studies. Atherosclerosis 234, 11-16.

13. Fung TT, Malik V, Rexrode KM, et al. (2009) Sweetened beverage consumption and risk of coronary heart disease in women. Am J Clin Nutr 89, 1037-1042.

14. Malik VS, Popkin BM, Bray GA, et al. (2010) Sugar-sweetened beverages, obesity, type 2 diabetes mellitus, and cardiovascular disease risk. Circulation 121, 1356-1364.

15. Denova-Gutiérrez E, Talavera JO, Huitrón-Bravo G, et al. (2010) Sweetened beverage consumption and increased risk of metabolic syndrome in Mexican adults. Public Health Nutr 13, 835-842.

16. Barquera S, Hernandez L, Tolentino ML, et al. (2008) Energy intake from beverages is increasing in Mexican adolescents and adults. $J$ Nutr 138, 2454-2461.

17. Stern D, Piernas C, Barquera S, et al. (2014) Caloric beverages were major source of energy among children and adults in Mexico, 1999-2012. J Nutr 144, 949-956.

18. Hu FB (2002) Dietary pattern analysis: a new direction in nutritional epidemiology. Curr Opin Lipidol 13, 3-9.

19. Denova-Gutiérrez E, Flores YN, Gallegos-Carrillo K, et al. (2016) Health workers cohort study: methods and study design. Salud Publica Mex 58, 708-716.

20. Rosner B (1983) Percentage points for a generalized ESD many-outlier procedure. Technometrics 25, 165-172.

21. Hernández-Avila M, Romieu I, Parra S, et al. (1998) Validity and reproducibility of a food frequency questionnaire to assess dietary intake of women living in Mexico City. Salud Publica Mex 40, 133-140.

22. Hernández-Avila M, Resoles M, Parra S, et al. (2003) Sistema de Evaluación de Hábitos Nutricionales y Consumo de Nutrimentos (SNUT). Cuernavaca: INSP.

23. Arranz S, Chiva-Blanch G, Valderas-Martínez P, et al. (2012) Wine, beer, alcohol and polyphenols on cardiovascular disease and cancer. Nutrients 4, 759-781.

24. Denova-Gutiérrez E, Tucker KL, Flores M, et al. (2016) Dietary patterns are associated with predicted cardiovascular disease risk in an urban Mexican adult population. J Nutr 146, 90-97.

25. Martínez González MA, López FC, Varo JJ, et al. (2005) Validation of the Spanish version of the physical activity questionnaire used in the Nurses 'Health Study and the Health Professionals' Follow-up Study. Public Health Nutr 8, 920-927.

26. Flores YN, Auslander A, Crespi CM, et al. (2016) Longitudinal association of obesity, metabolic syndrome and diabetes with risk of elevated aminotransferase levels in a cohort of Mexican health workers. J Dig Dis 17, 304-312.

27. Tate JR, Rifai N, Berg K, et al. (1998) International Federation of Clinical Chemistry and Laboratory Medicine (IFCC) standardization project for the measurement pf lipoprotein(a). Phase 2: selection and properties of a proposed secondary reference material for lipoprotein(a). Clin Chem 44, 1629-1640.

28. National Cholesterol Education Program, National Heart, Lung and Blood Institute \& National Institute of Health (2001) Detection, Evaluation and Treatment of High Blood Cholesterol in Adults (Adults Treatment Panel III), Executive Summary,' Third Report of the National Cholesterol Education Program (NCEP) Expert Panel, 10-3670:16. Bethesda, MD: National Institutes of Health.

29. D'Agostino RB, Grundy S, Sullivan LM, et al. (2001) Validation of the Framingham coronary heart disease prediction scores: results of a multiple ethnic groups investigation. JAMA $\mathbf{2 8 6}$, 180-187. 
30. Flint AJ, Rexrode KM, Hu FB, et al. (2010) Body mass index, waist circumference, and risk of coronary heart disease: a prospective study among men and women. Obes Res Clin Prac 4, 71-81.

31. Wang $Z \&$ Nakayama $T$ (2010) Inflammation, a link between obesity and cardiovascular disease. Mediators Inflamm 2010, 535918.

32. Mukamal KJ, Conigrave KM, Mittleman MA, et al. (2003) Roles of drinking pattern and type of alcohol consumed in coronary heart disease in men. $N$ Engl J Med 348, 109-118.

33. Rajpathak SN, Freiberg MS, Wang C, et al. (2010) Alcohol consumption and the risk of coronary heart disease in postmenopausal women with diabetes: Women's Health Initiative Observational Study. Eur J Nutr 49, 211-218.

34. Ronksley PE, Brien SE, Turner BJ, et al. (2011) Association of alcohol consumption with selected cardiovascular disease outcomes: a systematic review and meta-analysis. BMJ 342, d671.

35. Van de Wiel A (2012) The effect of alcohol on postprandial and fasting triglycerides. Int J Vasc Med 2012, 862504.

36. Duffey KJ, Steffen LM, Van Horn L, et al. (2012) Dietary patterns matter: diet beverages and cardiometabolic risks in the longitudinal Coronary Artery Risk Development in Young Adults (CARDIA) Study. Am J Clin Nutr 95, 909-915.

37. Dhingra R, Sullivan L, Jacques PF, et al. (2007) Soft drink consumption and risk of developing cardiometabolic risk factors and the metabolic syndrome in middle-aged adults in the community. Circulation 116, 480-488.

38. Hoare E, Varsamis P, Owen N, et al. (2017) Sugar-and intensesweetened drinks in Australia: a systematic review on cardiometabolic risk. Nutrients 9, 1075.

39. Khan TA \& Sievenpiper JL (2016) Controversies about sugars: results from systematic reviews and meta-analyses on obesity, cardiometabolic disease and diabetes. Eur J Nutr 55, 25-43.

40. Tokunaga S, White IR, Frost C, et al. (2002) Green tea consumption and serum lipids and lipoproteins in a population of healthy workers in Japan. Ann Epidemiol 12, 157-165.

41. Davies MJ, Judd JT, Baer DJ, et al. (2003) Black tea consumption reduces total and LDL cholesterol in mildly hypercholesterolemic adults. J Nutr 133, 3298S-3302S.

42. Hino A, Adachi H, Enomoto M, et al. (2007) Habitual coffee but not green tea consumption is inversely associated with metabolic syndrome: an epidemiological study in a general Japanese population. Diabetes Res Clin Pract 76, 383-389.

43. Kim A, Chiu A, Barone MK, et al. (2011) Green tea catechins decrease total and low-density lipoprotein cholesterol: a systematic review and meta-analysis. J Am Diet Assoc 111, 1720-1729.
44. Suzuki Y, Miyoshi N \& Isemura M (2012) Health-promoting effects of green tea. Proc Jpn Acad Ser B Phys Biol Sci $\mathbf{8 8}$, 88-101.

45. Higdon JV \& Frei B (2006) Coffee and health: a review of recent human research. Crit Rev Food Sci Nutr $\mathbf{4 6}$, 101-123.

46. van Dongen LH, Mölenberg FJ, Soedamah-Muthu SS, et al. (2017) Coffee consumption after myocardial infarction and risk of cardiovascular mortality: a prospective analysis in the Alpha Omega Cohort. Am J Clin Nutr 106, 1113-1120.

47. Kouli GM, Panagiotakos DB, Georgousopoulou EN, et al. (2018) J-shaped relationship between habitual coffee consumption and 10-year (2002-2012) cardiovascular disease incidence: the ATTICA study. Eur J Nutr 57, 1677-1685.

48. Ikeda I, Imasato Y, Sasaki E, et al. (1992) Tea catechins decrease micellar solubility and intestinal absorption of cholesterol in rats. Biochim Biophys Acta 1127, 141-146.

49. Ness AR, Smith GD \& Hart C (2001) Milk, coronary heart disease and mortality. J Epidemiol Community Health 55 , 379-382.

50. Elwood PC, Strain JJ, Robson PJ, et al. (2005) Milk consumption, stroke, and heart attack risk: evidence from the Caerphilly cohort of older men. J Epidemiol Community Health 59, 502-505.

51. Jakobsen MU, O'Reilly EJ, Heitmann BL, et al. (2009) Major types of dietary fat and risk of coronary heart disease: a pooled analysis of 11 cohort studies. Am J Clin Nutr 89, $1425-1432$

52. Allender PS, Cutler JA, Follmann D, et al. (1996) Dietary calcium and blood pressure: a meta-analysis of randomized clinical trials. Ann Intern Med 124, 825-831.

53. Bucher HC, Cook RJ, Guyatt GH, et al. (1996) Effects of dietary calcium supplementation on blood pressure. A meta-analysis of randomised controlled trials. JAMA 275, 1016-1022.

54. Mensink RP, Zock PL, Kester AD, et al. (2003) Effects of dietary fatty acids and carbohydrates on the ratio of serum total to HDL cholesterol and on serum lipids and apolipoproteins: a meta-analysis of 60 controlled trials. Am J Clin Nutr 77, 1146-1155.

55. Maas AH \& Appelman YE (2010) Gender differences in coronary heart disease. Neth Heart J 18, 598-602.

56. Denova-Gutiérrez E, Tucker KL, Salmerón J, et al. (2016) Relative validity of a food frequency questionnaire to identify dietary patterns in an adult Mexican population. Salud Publica Mex 58, 608-616. 